\title{
Complications Associated with The Occurrence of Impacted Mandibular Third Molars in Saudi Arabian Sub-Population: Najran Province Experience
}

\author{
Braimah Ramat Oyebunmi ${ }^{1 *}$, Dawood Ali-Alsuliman' ${ }^{1}$, Yahyah Alsalah ${ }^{1}$, Hakeem 0 Agbaje $^{2}$, \\ Nasser Naji Alalhareth ${ }^{1}$ and Nahal M Alsawas ${ }^{1}$ \\ ${ }^{1}$ Department of Oral and Maxillofacial Surgery, Najran Specialty Regional Dental Center, Shurfah Kingdom of Saudi Arabia. \\ ${ }^{2}$ Department of Orthodontics, International Medical Complex, Kingdom of Saudi Arabia
}

*Corresponding author: Braimah Ramat Oyebunmi, Department of Oral and Maxillofacial Surgery, Usmanu Danfodiyo University Teaching Hospital, Nigeria.

To Cite This Article: Braimah Ramat Oyebunmi. Complications Associated with The Occurrence of Impacted Mandibular Third Molars in Saudi Arabian Sub-Population: Najran Province Experience. Am J Biomed Sci \& Res. 2019 - 3(3). AJBSR.MS.ID.000669.

DOI: 10.34297/AJBSR.2019.03.000669

Received: May 23, 2019 | Published: June 10, 2019

\begin{abstract}
Introduction: Impacted third molars impaction is a global clinical condition that is rising. Literature is still lacking on the reported cases of associated pathologies with impacted mandibular third molars despite its richness in prevalence and its surgical removal.

Materials and Methods: This is a retrospective study with data such as gender and age of patients, special relationships of the impacted molars, reason for extraction, tooth extracted and associated pathologies collected from the Department of Oral and Maxillofacial Surgery, Najran Specialty Regional Dental Center, Najran Kingdom of Saudi Arabia from 2015-2018. The data were processed and analyzed using IBM SPSS software version 25 for IOS (Armonk, NY: IBM Corp).
\end{abstract}

Results: A total of 1024 mandibular third molar extractions was carried out during the study period from 609 (59.5\%) females and 415 (40.5\%) males (F:M = 1.5:1) (Table 1). Out of this number, 570 (55.7\%) had associated pathology with $270(47.4 \%)$ males and 300 (52.6\%) females and prevalence rate of $55.7 \%$. The age ranged from 17 to 69 years (mean \pm SD, $31.4 \pm 9.6$ years) with majority in the age group (21-30) years. Distal caries on the second molar tooth accounted for the highest number of associated pathologies $193(18.8 \%)$ followed closely by pocket alone between the second and third molars 157 (15.3\%).

Conclusion: Distal second molar root caries and pocket formation between the impacted tooth and second molar tooth was the most associated pathology with the impacted molar in the current study. These were frequently associated with a mesio-angular impaction

Keywords: Associated pathology; Caries; Mandibular third molar

Abbrevations: D7C: Distal 7Caries; D7RR: Distal 7 Root Resorption; POCK: Pocket; D7C+POCK: Distal 7Caries+Pocket; D7RR+POCK: Distal 7 Root Resorption+Pocket; MA: Mesioangular; VER: Vertical; DA: Distoangular; HOR: Horizontal.

\section{Introduction}

Apt assessment of retained third molars when local symptoms are present, should incorporate all-inclusive clinical and radiographic evaluation [1]. Because of limitations in the use of periapical radiographs to properly assess impacted third molars, panoramic radiograph is highly advocated [1]. Impacted third molars impaction is a global clinical condition that is rising
[2]. Literature is still lacking on the reported cases of associated pathologies with impacted mandibular third molars despite its richness in prevalence and its surgical removal [3,4]. When impacted mandibular molars are symptoms free, it does not necessarily relate to lack of other pathologic conditions [5]. Also, symptoms associated with the sequelae of presence and removal 
of impacted mandibular third molars affects oral health related quality of life of patient [6,7]. Reported pathologies that are associated with retained and impacted third molars include; cystic lesions, neoplasms, pericoronitis, periodontitis and pathological root resorption as well as injurious effects on the adjacent molar teeth especially distal caries formation [8]. In African population, Braimah et al. [9] has reported pathologies associated with impacted mandibular third molars from Nigeria, while in the Arab world Ma'aita J.K [10] has reported such condition in Jordanian patients. In Saudi population studies on pathologies associated with impacted third molars have been conducted in Al-Jouf and Jeddah $[8,11]$, none has been reported in Najran, South-west province of the kingdom. The aim of the current study is to report associated pathologies with impacted mandibular molars in Najran, southwest region of Saudi Arabia.

\section{Materials and Methods}

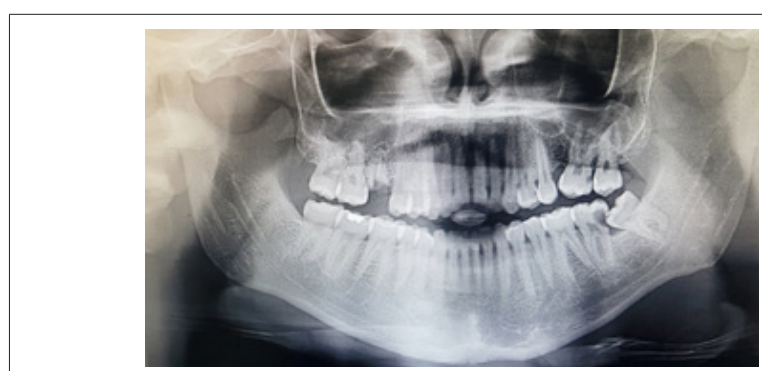

Figure 1: Panoramic view showing second mandibular molar distal caries.

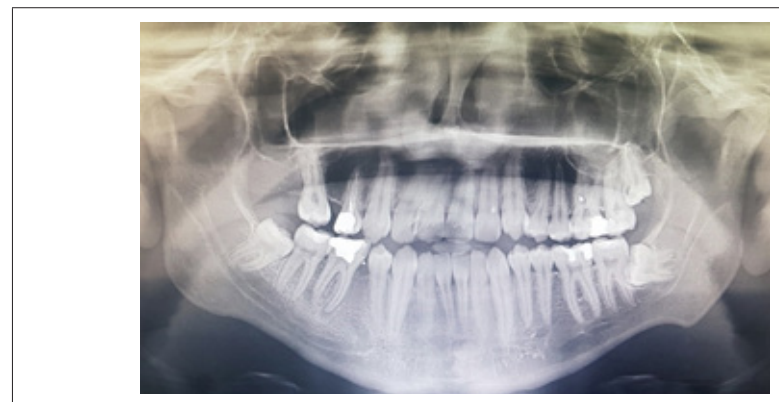

Figure 2: Panoramic view showing second mandibular molar distal root resorption.

The purpose of the current study is to find out associated pathologies with impacted mandibular third molar in Najran, Kingdom of Saudi Arabia. This is a retrospective study with data such as gender and age of patients, special relationships of the impacted molars, reason for extraction, tooth extracted and associated pathologies collected from the Department of Oral and Maxillofacial Surgery, Najran Specialty Regional Dental Center, Najran Kingdom of Saudi Arabia from 2015-2018. The Department of the Centre has a large catchment area serving Najran province and neighboring Yemen with over 600,000 people. All panaoramic radiographs of patients presenting for mandibular third molar extraction were retrieved and carefully checked for spatial relationships and any form of pathology in relation to the impacted tooth. Spatial relationships was based on Winter's classification [12] (mesio-angular, disto-angular, vertical and horizontal). Associated pathologies investigated include; D7C (Distal 7caries) (Figure 1),
D7RR (Distal 7 root resorption) (Figure 2), POCK (Pocket) (Figure 3), D7C+POCK (Distal 7 caries+Pocket) (Figure 4), D7RR+POCK (Distal 7 root resorption+Pocket) (Figure 5) and Cysts (Figure 6). Cases of incomplete record and without panoramic radiographs were excluded.

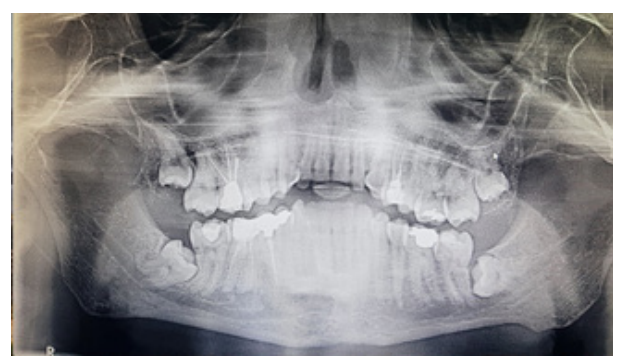

Figure 3: Panoramic view showing pocket formation between second and third mandibular molar.

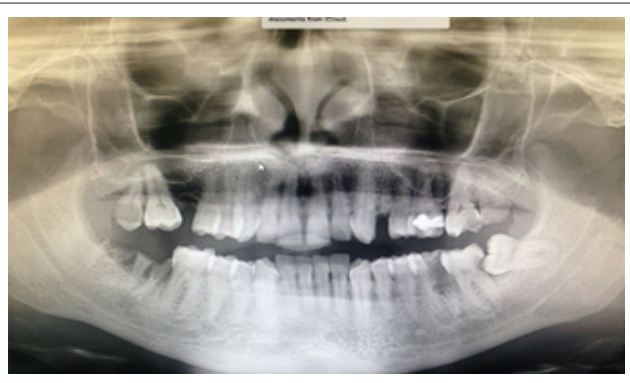

Figure 4: Panoramic view showing second mandibular molar distal caries and pocket formation between it and third mandibular molar.

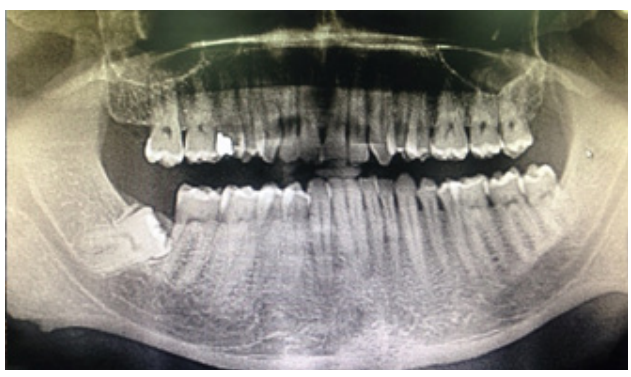

Figure 5: Panoramic view showing second mandibular molar distal root resorption and pocket formation between it and third mandibular molar.

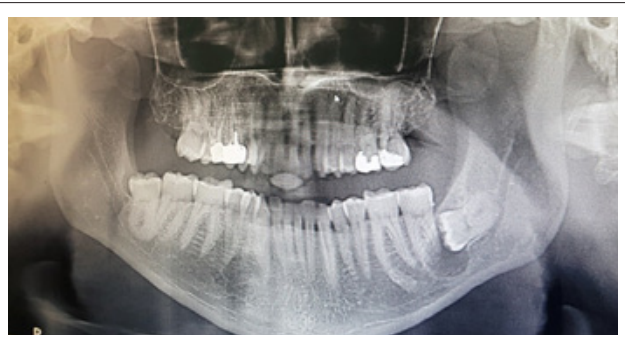

Figure 6: Panoramic view showing cyst formation around third mandibular molar.

Data analysis was carried out using IBM SPSS Statistics for windows Version 25 (Armonk, NY: IBM Corp) and results shall be presented as simple frequencies and descriptive statistics. A p value less than 0.05 shall be considered significant. 


\section{Results and Discussion}

Table 1: Distribution of associated pathologies according to gender of patients.

\begin{tabular}{|c|c|c|c|}
\hline & \multicolumn{2}{|c|}{ Gender } & Total (\%) \\
\hline D7C & Male (\%) & Female (\%) & $193(18.8)$ \\
\hline D7RR & $68(6.6)$ & $128(12.5)$ & $6(0.8)$ \\
\hline POCK & $2(0.2)$ & $70(6.8)$ & $157(15.3)$ \\
\hline D7C+POCK & $87(8.5)$ & $40(3.9)$ & $102(10.0)$ \\
\hline D7RR+POCK & $62(6.1)$ & $20(2.0)$ & $45(4.4)$ \\
\hline CYST & $25(2.4)$ & $36(3.5)$ & $62(6.0)$ \\
\hline CYST+CARIES & $26(2.5)$ & $0(0.0)$ & $3(0.3)$ \\
\hline NONE & $3(0.3)$ & $309(30.2)$ & $454(44.3)$ \\
\hline TOTAL & $145(14.1)$ & $609(59.5)$ & $1024(100.0)$ \\
\hline
\end{tabular}

Note: $x 2=58.92, \mathrm{df}=7, \mathrm{p}$ value $=0.000$

Key: D7C (Distal 7 caries), D7RR (Distal 7 root resorption), POCK (Pocket), D7C+POCK (Distal 7 caries+Pocket), D7RR+POCK (Distal 7 root resorption+Pocket)

Figure 7: Pie-chart showing distribution of gender with associated complications with impacted mandibular third molar.

\begin{tabular}{|c|c|c|c|c|c|c|c|}
\hline & \multicolumn{6}{|c|}{ Age group } & \multirow[b]{2}{*}{$\begin{array}{c}\text { Total } \\
(\%)\end{array}$} \\
\hline & $\begin{array}{c}11-20 \\
(\%)\end{array}$ & $\begin{array}{c}21-30 \\
(\%)\end{array}$ & $\begin{array}{c}31-40 \\
(\%)\end{array}$ & $\begin{array}{c}41-50 \\
(\%)\end{array}$ & $\begin{array}{c}51-60 \\
(\%)\end{array}$ & $\begin{array}{c}\text { 61-70 } \\
(\%)\end{array}$ & \\
\hline D7C & $22(2.1)$ & $69(6.8)$ & $74(7.2)$ & $25(2.4)$ & $3(0.3)$ & $0(0.0)$ & 193 (18.8) \\
\hline D7RR & $0(0.0)$ & $6(0.6)$ & $1(0.1)$ & $0(0.0)$ & $0(0.0)$ & $1(0.1)$ & $8(0.8)$ \\
\hline POCK & $1(0.1)$ & $79(7.7)$ & $8(0.8)$ & $45(4.4)$ & $21(2.1)$ & $3(0.3)$ & 157 (15.3) \\
\hline D7C+POCK & $0(0.0)$ & $62(6.1)$ & $35(3.4)$ & $5(0.5)$ & $0(0.0)$ & $0(0.0)$ & $102(10.0)$ \\
\hline D7RR+POCK & $0(0.0)$ & $45(4.4)$ & $0(0.0)$ & $0(0.0)$ & $0(0.0)$ & $0(0.0)$ & $45(4.4)$ \\
\hline CYST & $0(0.0)$ & $31(3.0)$ & $28(2.7)$ & $2(0.2)$ & $0(0.0)$ & $1(0.1)$ & $62(6.1)$ \\
\hline CYST+CARIES & $0(0.0)$ & $1(0.1)$ & $2(0.2)$ & $0(0.0)$ & $0(0.0)$ & $0(0.0)$ & $3(0.3)$ \\
\hline NONE & $5(0.5)$ & $241(23.5)$ & $126(12.3)$ & $55(5.4)$ & $26(2.5)$ & $1(0.1)$ & $454(44.3)$ \\
\hline TOTAL & $28(2.7)$ & $534(52.1)$ & $274(26.8)$ & $132(12.9)$ & $50(4.9)$ & $6(0.6)$ & $1024(100.0)$ \\
\hline
\end{tabular}

Note: $x^{2}=274.695, d f=35, p$ value $=0.000$

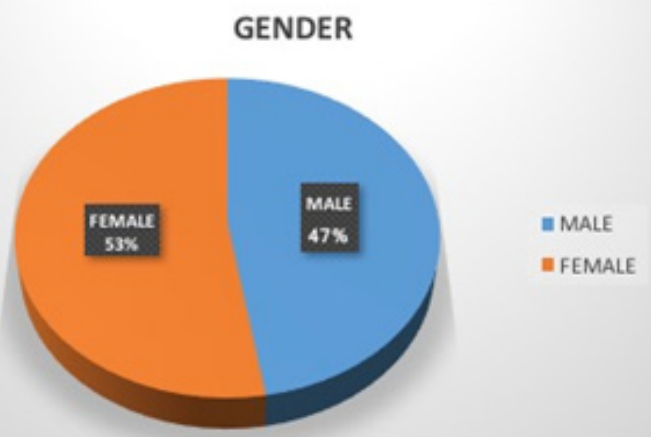

Key: D7C (Distal 7 caries), D7RR (Distal 7 root resorption), POCK (Pocket), D7C+POCK (Distal 7 caries+Pocket), D7RR+POCK (Distal 7 root resorption+Pocket)

A total of 1024 mandibular third molar extractions was carried out during the study period from 609 (59.5\%) females and 415 (40.5\%) males (F:M = 1.5:1) (Table 1 \& Figure 7). Out of this number, $570(55.7 \%)$ had associated pathology with $270(47.4 \%)$ males and
$300(52.6 \%)$ females and prevalence rate of $55.7 \%$. The age ranged from 17 to 69 years (mean \pm SD, $31.4 \pm 9$.6years) with majority in the age group (21-30) years (Table 2). There was significant difference when the associated pathology was compared with gender of the 
patient $(\chi 2=58.92, \mathrm{df}=7, \mathrm{P}=0.000)$. Other associated pathologies were as shown in Table 1. It was observed that most of the cases without associated pathology were seen in the age groups 21-30 years and 31-40 years (241(23.5\%) and 126 (12.3\%) respectively) with a statistically significant difference of $(\chi 2=274.695, \mathrm{df}=35$, $P=0.000$ ) (Table 2). When associated pathology was correlated with spatial relationship of the impacted mandibular third molar, mesio-angular impaction was mostly associated with pathology 418 (40.8\%), while disto-angular impaction less associated with pathology 197 (19.2\%), with a statistical significant difference of $\mathrm{P}=0.000$ (Table 3).

\begin{tabular}{|c|c|c|c|c|c|}
\hline & \multicolumn{4}{|c|}{ Spatial relation } & \multirow[b]{2}{*}{ Total (\%) } \\
\hline & MA (\%) & VER (\%) & DA (\%) & HOR (\%) & \\
\hline D7C & $117(11.4)$ & $22(2.1)$ & $4(0.4)$ & 50 (4.9) & 193 (18.8) \\
\hline D7RR & $7(0.7)$ & $0(0.0)$ & $0(0.0)$ & $1(0.1)$ & $8(0.8)$ \\
\hline POCK & $94(9.2)$ & $58(5.7)$ & $4(0.4)$ & $1(0.1)$ & 157 (15.3) \\
\hline $\mathrm{D} 7 \mathrm{C}+\mathrm{POCK}$ & $96(9.4)$ & $0(0.0)$ & $2(0.2)$ & $4(0.4)$ & $102(10.2)$ \\
\hline D7RR+POCK & $0(0.0)$ & $0(0.0)$ & $0(0.0)$ & $45(4.4)$ & $45(4.4)$ \\
\hline CYST & $10(1.0)$ & $48(4.7)$ & $4(0.4)$ & $0(0.0)$ & $62(6.1)$ \\
\hline CYST+CARIES & $2(0.2)$ & $1(0.1)$ & $0(0.0)$ & $0(0.0)$ & $3(0.3)$ \\
\hline NONE & $92(9.0)$ & $150(14.7)$ & $183(17.9)$ & $29(2.8)$ & $454(44.3)$ \\
\hline TOTAL & $418(40.8)$ & 279 (27.2) & 197 (19.2) & 130 (12.7) & $1024(100.0)$ \\
\hline
\end{tabular}

Note: $\mathrm{X} 2=843.50, \mathrm{df}=21, \mathrm{p}$ value $=0.000$

Key: D7C (Distal 7 caries), D7RR (Distal 7 root resorption), POCK (Pocket), D7C+POCK (Distal 7 caries+Pocket), D7RR+POCK (Distal 7 root resorption+Pocket), MA (Mesioangular), VER (Vertical), DA (Distoangular), HOR (Horizontal).

Disagreements continues to swirl the issue of third molar retention among researchers and clinicians despite several informed reasons to make the clinician take a position [4]. As the controversies persists, advocates of retaining third molars have justified this by the morbidity associated with the surgical extraction of these teeth [4]. Similarly, lack of symptoms have also been a reason for retaining impacted third molars [13]. Other clinicians have recommended a wait and see approach and when symptomatic should be removed $[14,15]$. Very few studies have reported early removal based on possibility of associated pathologies with the impacted tooth [5]. It is therefore important that retained wisdom teeth are judiciously checked for signs of pathology because most of them are either impacted or partially erupted [1]. Female predilection was observed in this study which has upheld previous findings on gender predilection of third molars $[16,17]$. This has been attributed to growth factors favoring male jaw growth during period of eruption of third molars as compared to females [18]. Other studies however have found no gender predilection $[19,20]$. Despite age of patients in the current study ranging from 17-69 years, majority fell within age group 21-30 years. This age group has been reported as the commonest age of presentation for the removal of impacted third molars [2123]. To our surprise, this younger age group had more associated pathology with the retained third molar, although, older age group has been reported to have more of associated pathology [1,4]. In a Jordanian study, older age group has been reported due to lack of early presentation [10]. In terms of indications for third molar extraction, caries and its sequelae and pericoronitis accounted for most of the reasons for third molar extraction. This was supported by previous studies on the indications for third molar removal [9,24]. Chronic pericoronitis was the most common indication for surgical extraction of mandibular third molar (490 (47.9\%)) in the study population followed by apical periodontitis (427 $(41.7 \% \%)$ (Figure 8). Mesio-angular impaction was the most frequent spatial relation of the impacted mandibular molar to the lower second molar tooth (418 (40.8\%)), followed by vertical impaction 279 $(27.2 \%)$, others are as shown in (Table 3 ).

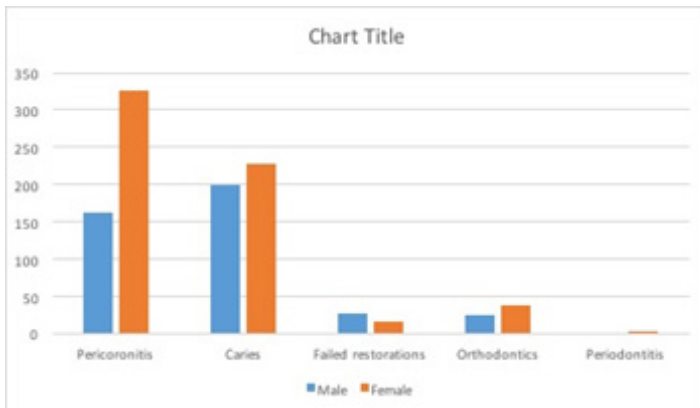

Figure 8: Bar-chart showing distribution of indication for surgical removal according to gender of patients. 
Latest evidence has suggested an increase in periodontal probing depts. Associated with an impacted mandibular third molar [25]. This current study has reported a prevalence of $15.3 \%$. Braimah et al. [9] has reported a higher prevalence (23.7\%) from a sub-Saharan African study, while Chu et al. [24] has reported a rate of $8.8 \%$ among the Chinese population. The exploratory depths leads to stagnation areas for pathological bacteria proliferation that will further lead to deep periodontal disease [26,27]. We also observed that deep probing depths were also associated with other pathological conditions like caries and root resorption. This combined pathologies have been reported in the literature [9].

Distal caries on the second molar tooth accounted for the highest number of associated pathologies 193 (18.8\%) followed closely by pocket alone between the second and third molars 157 (15.3\%). Distal surface of second mandibular tooth caries has been reported as a common pathology associated impacted lower third molar especially the mesio angular impaction because of the angulation $[9,28]$. This study have also recorded distal surface root caries as the most frequent complication with the presence of an impacted mandibular third molar tooth $[9,29]$. Similar to other studies, they are most seen with mesio angular impaction because of stagnation and difficult to clean. Distal second molar root resorption is still a debated complication with impacted lower third molar. Some studies have reported it [30,31] while others did not find any $[9,32,33]$. Our study has reported $8(0.8)$ patient having this pathology. Reasons for this controversies have been reported to be the difficulty in distinguishing radiologically between it and distal surface caries [34].

\section{Conclusion}

Distal second molar root caries and pocket formation between the impacted tooth and second molar tooth was the most frequent associated pathology with the impacted molar in the current study. Dental practitioners should be aware and look out for these associated pathologies in order to take informed decision on removal or retention of an impacted teeth when symptomatic or not.

\section{Acknowledgment}

The authors will like to appreciate the efforts of Miss Fatima Fakkai of the nursing department for her help in data collection.

\section{Conflict of interest}

The authors declare no conflict of interests.

\section{References}

1. Haddad AJ, Talwar RM, Clokie CML (2006) The Importance of Recognizing Pathology Associated with Retained Third Molars. Journal of Canadian Dental Association 72(1): 41-45.

2. Owotade FJ (1999) Current concepts in the management of impacted third molars. Nig J Med 8: 135-138.

3. Obiechina AE, Arotiba JT, Fasola AO (2001) Third molar impaction: evaluation of the symptoms and pattern of impaction of mandibular third molar teeth in Nigerians. Odontostomatol Trop 24(93): 22-25.

4. Campbell JH (2013) Pathology Associated with the Third Molar. Oral Maxillofacial Surg Clin N Am 25(1): 1-10.
5. White RP, Proffit WR (2011) Evaluation and management of asymptomatic third molars: lack of symptoms does not equate to lack of pathology. Am J Orthod Dentofacial Orthop 140(1): 10-16.

6. Braimah RO, Ndukwe KC, Owotade FJ, Aregbesola SB (2016) Oral Health Related Quality of Life (OHRQoL) following third molar surgery in SubSaharan Africans: an observational study. Pan Afr Med J 25: 97

7. Braimah RO, Ndukwe KC, Owotade FJ, Aregbesola SB (2017) Impact of oral antibiotics on health related quality of life outcomes in Nigerian patients following mandibular third molar surgery. Niger J Clin Pract 20(9): 1189-1194.

8. Khawaja NA, Khalil H, Parveen K, Al-Mutiri A, Al-Mutiri S, et al. (2015) A Retrospective Radiographic Survey of Pathology Associated with Impacted Third Molars among Patients Seen in Oral \& Maxillofacial Surgery Clinic of College of Dentistry, Riyadh. J Int Oral Health 7(4): 1317.

9. Braimah RO, Ibikunle AA, Taiwo AO, Kizito Chioma Ndukwe, John Foluso Owotade, et al. (2018) Pathologies associated with impacted mandibular third molars in Sub-Saharan Africans. Dent Med Res 6(1): 2-6.

10. Ma'aita JK. Impacted third molars and associated associated pathology in Jordanian patients Saudi Dental Journal 12(1): 16-19.

11. Santosh P (2015) Impacted Mandibular Third Molars: Review of Literature and a Proposal of a: Combined Clinical and Radiological Classification. Ann Med Health Sci Res 5(4): 229-234.

12. Winter GB (1926) Principles of exodontias as applied to impacted mandibular third molar. ( $3^{\text {rd }}$ edn), American Medical Book Co; St Louis (MO), USA, pp. 1926.

13. Sasano T, Kuribara N, Iikubo M, Yoshida A, Satoh-Kuiriwada S, et al. (2003) Influence of angular position and degree of impaction of third molars on development of symptoms: long-term follow-up under good oral hygiene conditions. Toho- ku J Exp Med 200(2):75-83.

14. Kandasamy S (2011) Evaluation and management of asymptomatic third molars: watchful monitoring is a low-risk alternative to extraction. Am J Orthod Dentofacial Orthop 140(1): 11-17.

15. Hill CM (2006) Removal of asymptomatic third molars: an opposing view. J Oral Maxillofac Surg 64(12): 1816-1820.

16. Quek SL, Tay CK, Tay KH, Toh SL, Lim KC (2003) Pattern of third molar impaction in a Singapore Chinese population: a retrospective radiographic survey. Int J Oral Maxillafac Surg 32(5): 548-552.

17. Ma'aita J, Alwrikat A (2000) Is the mandibular third molar a risk factor for mandibular angle fracture? . Oral Surg Oral Med Oral Pathol Oral Radiol Endod 89(2): 143-146.

18. Bishara SE (1992) Impacted maxillary canines: a review. Am J Orthod Dentofacial Orthop 101(2): 159-171.

19. Kaya GS, Aslan M, Ömezli MM, Dayi E (2010) Some morphological features related to mandibular third molar impaction. J Clin Exp Dent 2:12-17.

20. Hattab FN, Rawashdeh MA, Fahmy MS (1995) Impaction status of third molars in Jordanian students. Oral Surg Oral Med Oral Pathol Radiol Endod 79(1): 24-29.

21. Gisakis IG, Palamidakis FD, Farmakis ET, Kamberos G, Kamberos S (2011) Prevalence of impacted teeth in a Greek population. Journal of Investigative and Clinical Dentistry 2(2): 102-109.

22. Shetty DC (2010) Epidemiological Status of 3rd Molars-Their Clinical Implications. J Oral Health Comm Dent 4: 12-15.

23. Breik 0, Grubor D (2008) The incidence of mandibular third molar impactions in different skeletal face types. Aust Dent J 53(4): 320-324.

24. Chu FCS, Li TKL, Lui VKB, et al. Prevalence of impacted teeth and associated pathologies-a radiographic study of the Hong Kong Chinese population. Hong Kong Med J 9(3): 158-163. 
25. Blakey GH, Marciani RD, Haug RH, Phillips C, Offenbacher S, et al. (2002) Periodontal pathology associated with asymptomatic third molars. Oral Maxillofac Surg 60(11): 1227-1233.

26. Mansfield JM, Campbell JH, Bhandari AR, Jesionowski AM, Vickerman MM, et al. (2012) Molecular analysis of $16 \mathrm{~S}$ rRNA genes identifies potentially pathogenic bacteria and archaea in the plaque of partially erupted third molars. J Oral Maxillofac Surg 70(7): 1507-1514.

27. White RP, Madianos PN, Offenbacher S, Phillips C, Blakey GH, et al (2002) Microbial complexes detected in the second/third molar region in patients with asymptomatic third molars. J Oral Maxillofac Surg 60(11): 1234-1240.

28. Polat HB, Ozan F, Kara I, Ozdemir H, Ay S (2008) Prevalence of commonly found pathoses associated with mandibular impacted third molars based on panoramic radiographs in Turkish population. Oral Surg Oral Med Oral Pathol Oral Radiol Endod 105(6): e41-e47.

29. Ahmad N, Gelesko S, Shugars D, White RP Jr, Blakey G, et al. (2008) Caries experienceand periodontal pathology in erupting third molars. J Oral Maxillofac Surg 66(5): 948-953.
30. Nitzan D, Keren T, Marmary T (1981) Does an impacted tooth cause root resorption of the adjacent one?. Oral Surg Oral Med Oral Pathol 51(3): 221-224.

31. Kahl B, Gerlach KL, Hilgers RD (1994) A long-term, follow-up, radiographic evaluation of asymptomatic impacted third molars in orthodontically treated patients. Int J Oral Maxillofac Surg 23(5): 279285 .

32. Ahlqwist M, Grondahl HG (1991) Prevalence of impacted teeth and associated pathology in middle-aged and older Swedish women. Community Dent Oral Epidemiol 19(2): 116-119.

33. Sewerin I, von Wowern N (1990) A radiographic four-year follow-up study of asymptomatic mandibular third molars in young adults. Int Dent J 40(1): 24-30.

34. Stanley HR, Alattar M, Collett WK, Stringfellow HR, Spiegel EH (1988) Pathological sequelae of "neglected" impacted third molars. J Oral Pathol 17(3): 113-117. 